\title{
INTRACRANIAL BRUITS IN INFANTS AND CHILDREN
}

\author{
BY \\ ROBERT HUGHES and R. MCLAREN TODD \\ From the Neurological Clinic, Royal Southern Hospital, Liverpool, and Alder Hey Children's Hospital, Liverpool
}

(RECEIVED FOR PUBLICATION MARCH 3, 1953)

The first recorded description of intracranial bruits was by Fisher (1834) who heard a 'cephalic bellows sound' in six children suffering from hydrocephalus. He thought that the sound was arterial in origin and that it was produced by pressure of the distended brain on the arteries at the base. The first description in this country was by Smyth (1837 and 1839) who heard a cerebral murmur in four children suffering from hydrocephalus. German and French physicians took an active interest in this murmur and their observations were reviewed by Jurasz (1877) and Epstein (1878). These writings reflect differences of opinion as to the significance of intracranial bruits, some observers maintaining that they were physiological and others that they were due to pathological conditions such as hydrocephalus, anaemia or rickets. Jurasz thought that the murmur developed because of a temporary relative stenosis of the carotid artery in the carotid canal, the foramen of which did not enlarge suffciently rapidly. Henoch (1889) held that the murmur was of no interest from a clinical point of view and that it could not be turned to account for diagnosis. Osler (1880) also thought that the murmur had no special pathological significance. Still (1921) heard a cephalic bruit in $\mathbf{3 0}$ out of $\mathbf{2 0 0}$ children but he was unable to connect the bruit with any particular morbid condition. Rickets and anaemia did not occur with any frequency in his cases. Hamburger (1931) reviewed the conditions which may give rise to head murmurs, including arteriovenous aneurysms, meningiomas, gliomas and atheromatous lesions in young patients. Ford (1944) considers that anaemia is the most common cause of benign intracranial bruits in infancy and childhood.

During the past 30 years little interest has been taken in intracranial bruits by the paediatrician and the general physician. The neurologist has regarded them of importance if other evidence of neurological disease was present. With the development of intracranial surgical technique and more recently of cerebral angiography this physical sign is now of the first importance and we thought it opportune to reinvestigate the frequency and significance of intracranial bruits in infancy and childhood.

\section{Present Investigations}

Three hundred and one patients under 16 years of age in two children's hospitals in Liverpool have been examined and an intracranial murmur was heard in 34 patients. The age distribution is given in Table 1, which also records Still's figures for com-

TABLE 1

\begin{tabular}{|c|c|c|c|c|c|c|}
\hline \multicolumn{4}{|c|}{ This Series } & \multicolumn{3}{|c|}{ Still (1921) } \\
\hline Age & Cases & Bruits & $\%$ & Cases & Bruits & $\%$ \\
\hline $\begin{array}{l}0- \\
1- \\
2- \\
3- \\
4- \\
5- \\
6- \\
7- \\
8- \\
9- \\
10- \\
11- \\
12- \\
13- \\
14- \\
15-16\end{array}$ & $\begin{array}{r}65 \\
28 \\
23 \\
24 \\
19 \\
26 \\
15 \\
21 \\
6 \\
10 \\
13 \\
16 \\
12 \\
9 \\
8 \\
6\end{array}$ & $\begin{array}{l}9 \\
5 \\
3 \\
3 \\
5 \\
3 \\
1 \\
2 \\
1 \\
0 \\
1 \\
0 \\
0 \\
1 \\
0 \\
0\end{array}$ & $\begin{array}{r}13 \cdot 8 \\
17 \cdot 8 \\
13 \cdot 0 \\
12 \cdot 5 \\
26 \cdot 3 \\
11 \cdot 5 \\
6 \cdot 6 \\
9 \cdot 5 \\
16 \cdot 6 \\
\overline{7 \cdot 7} \\
- \\
11 \cdot 1 \\
-\end{array}$ & $\begin{array}{r}47 \\
25 \\
16 \\
19 \\
23 \\
12 \\
10 \\
8 \\
11 \\
8 \\
7 \\
5 \\
1 \\
3 \\
2 \\
3\end{array}$ & $\begin{array}{r}\mathbf{7} \\
\mathbf{1 0} \\
\mathbf{2} \\
\mathbf{7} \\
\mathbf{0} \\
\mathbf{0} \\
\mathbf{1} \\
\mathbf{1} \\
\mathbf{0} \\
\mathbf{1} \\
\mathbf{0} \\
\mathbf{0} \\
\mathbf{0} \\
\mathbf{0} \\
\mathbf{0} \\
\mathbf{1}\end{array}$ & $\begin{array}{l}14 \cdot 9 \\
40 \\
12 \cdot 5 \\
36 \cdot 8 \\
\bar{Z} \\
10 \\
12 \cdot 5 \\
\overline{12 \cdot 5} \\
\overline{-} \\
\overline{-} \\
\overline{33 \cdot 3}\end{array}$ \\
\hline Totaks & 301 & 34 & $11 \%$ & 200 & 30 & $15 \%$ \\
\hline
\end{tabular}

parison. The children examined were suffering or convalescing from such common conditions as bronchitis, pneumonia, gastro-enteritis, congenital and rheumatic heart disease, and a few were being investigated for neurological disorders such as petit mal and hydrocephalus. The diagnoses of the patients in whom intracranial bruits were heard are recorded in Table 2, but the remaining 267 children were suffering from similar illnesses.

It was interesting to observe that in most of the children the breath sounds were distinctly heard while listening for the intracranial bruit, but the heart sounds could not be detected. In two children with congenital cardiac lesions an intracranial bruit was heard, but in 15 children with a loud cardiac murmur resulting from congenital or rheumatic 
TABLE 2

ILLNESSES OF CHILDREN WITH INTRACRANIAL BRUIT

Primary pulmonary tuberculosis

Bronchitis

Pneumonia

Feeding error

Burns

Glandular fever

Congenital heart disease

Empyema (convalescent)

Hydronephrosis

Upper respiratory tract infection

Coeliac disease

Meningococcal meningitis

Poliomyelitis

Abscess in groin

Tuberculous glands in neck

Fractured femur

Ervthema multiforme

Chorea

Hodgkin's disease

Nephritis

heart disease no intracranial bruit was heard. A number of children were suffering from conditions such as leukaemia in which marked anaemia was present but in none of these children was an intracranial bruit heard.

\section{Discussion}

Our observations are in agreement with those of Still (1921) that an intracranial bruit can be heard in 10 to $15^{\circ}$ of children suffering from some of the common clinical conditions. This bruit, which is best heard in the temporal region, varies in intensity, and, while in some children it is easily heard, in others it can only be heard when they stop breathing. Most observers agree that the bruit is arterial in origin and in our cases the bruit disappeared when the carotid artery was compressed. In some of our cases the cervical lymphatic glands were enlarged but not sufficiently to impede the flow of blood through the carotid arteries. We have not had an opportunity so far of examining at necropsy the internal carotid arteries of any of our patients in whom an intracranial bruit was heard during life. It is our intention, when opportunity offers, to outline the carotid arteries of such patients with latex, and to examine them with particular reference to calibre and tortuosity. It is possible that the petrous portion of the carotid artery may be narrowed as it passes through the bony carotid canal, and that the difference in calibre of this part of the artery and the intracranial (cavernous) portion may be responsible for the production of the bruit.

The frequency with which intracranial bruits are heard diminishes with age. In Still's series a bruit was heard in four out of 93 children aged 4 years or over compared with 26 out of 107 children under this age. In our series the bruit was heard in $15.7 \%$ of children under 5 years of age, in $9.1 \%$ aged 5 to 9 years, and in $3.4 \%$ aged 10 to 15 years. In adults, an intracranial bruit is heard infrequently, and when present it is usually indicative of organic disease, but in children an intracranial bruit is a relatively common finding; it is more likely to be heard in the younger age groups, and it does not usually indicate organic intracranial disease.

Idiopathic epilepsy is not an uncommon disorder in children; it would not therefore be surprising to find that some children had both an intracranial bruit and epilepsy. One such child, aged 7 years, not included in the present series, has been observed and bilateral angiograms performed but these did not reveal any vascular abnormality.

It has been found that cranial bruits (both 'functional' and organic) can easily be recorded with a phonocardiograph. Fig. 1 is a record of the bruit of the above child and Fig. 2 for comparison is a record of a bruit arising in a cerebral angioma in a woman of 40 years. In each case an E.C.G. (lead 2) is recorded simultaneously. It is of interest that both bruits when recorded show first and second sounds which cannot be distinguished clinically.
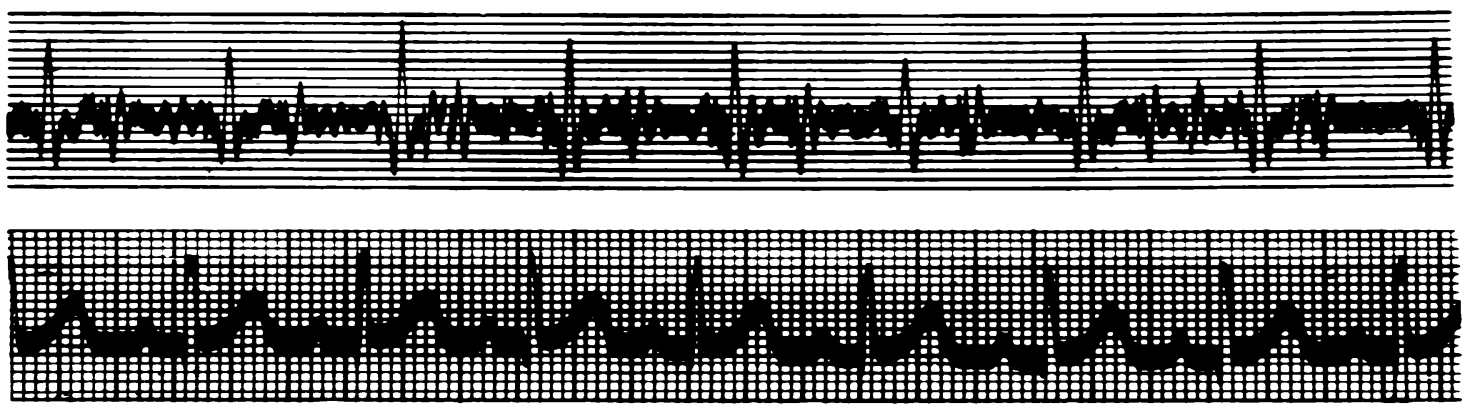

Fig. 1.-Phonocardiographic and electrocardiographic records from a girl aged 7 years in whom an intracranial bruit was heard but in whom bilateral cerebral angiograms showed no abnormality. 

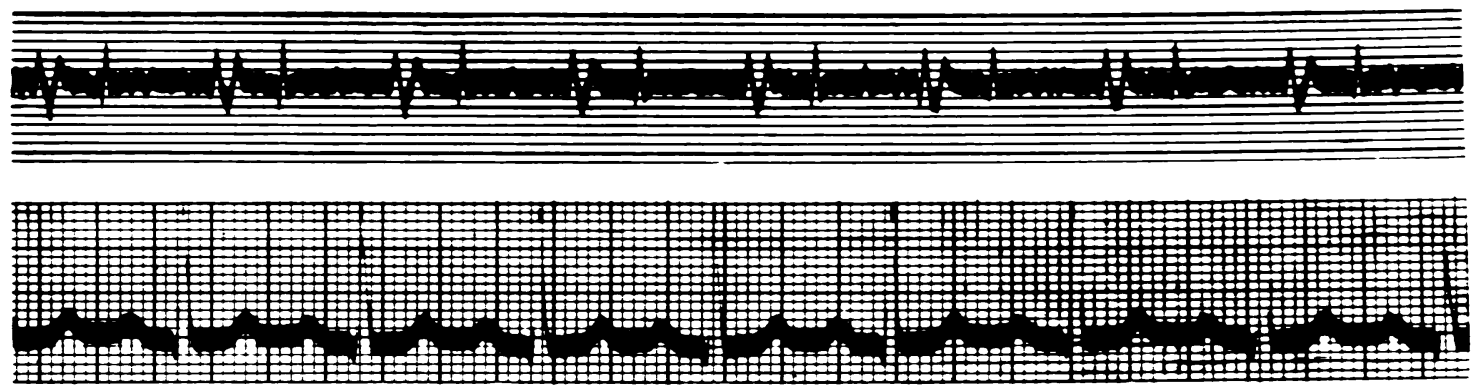

FIG. 2.-Phonocardiographic and electrocardiographic records from a woman aged 40 . Intracranial bruit uas heard and cerebrai angiograms revealed an angioma of the left farietal region.

\section{Conclusions}

From our observations it would be reasonable to conclude that the presence of an intracranial bruit in a child does not. of itself. indicate that an organic lesion. such as a cerebral aneurysm or vascular malformation. is present. and is not sufficient justification for subjecting children to cerebral angiography. or similar procedure.

We are indebted to Professor Sir Geoffrey Jefferson for his helpful criticism and to Mr. Caldwell for the phonocardiographs.

\section{REFERE $\backslash$ CES}

Epstein A 11878), Prag med II ichr. 3, 181.

Fisher. J D (1834). Med Mag Boston 2. 144

Ford. F. R. (1944). Diseases of the vervous Sistem in Int.r. . Crildhood and Adolescence. Ind ed. Springfield. Illinois.

Hamburger. L. P. (1931). Amer. J. med. Sci.. 181. 756

Henoch. E. (1889). Lectures on Children's Diseases. sol. 1. = 12 Neu Sydenham Society. London.

Jurasz. A. 11877). Das systolische Hirngeräusch der Kinder. He:de!therg.

Osler. W. (1880). Boston med. surg. J.. 103. 29

Osler. W. (1880). Boston med. vurg. J.. 103. 199

Smyth. J. R. (1837). Lond.
11839). Lancet. 1. 73.

G. F. 1921). Brit J Child. Dis.. 18, $1^{-3}$ 